\title{
Chapter 5 \\ Eighty Years of Sex-Specific \\ and Age-Specific Mortality Trends
}

\author{
France Meslé, Jacques Vallin, and Vladimir Shkolnikov
}

In Chaps. 2 and 3, we reconstructed annual sex-specific and age-specific mortality trends from the second quarter of the twentieth century, which had been seriously disrupted by the crises of the 1930s and 1940s; in Chap. 4, we were able to correct the standard estimates for the second half of the century, taking into account under-registration of deaths. From now on, therefore, we can work with a continuous series of life tables for each of the years 1927-2006 (see the complete time series in Annex II on the Website (http://www.demogr.mpg.de/books/drm/009 or http://extras.springer.com/) for the main functions of these life tables). ${ }^{1}$ Figure 5.1 provides an overview, tracing annual trends in life expectancy at birth for each sex over the course of the past 80 years.

In the Chaps. 2 and 3, our emphasis was above all on the extent of exceptional losses due to the two major crises of the past; here, however, we shall highlight long-term age-specific mortality trends, focusing in particular on the gradual change in age-specific mortality and the influence of mortality trends in each age group on the trend in life expectancy at birth.

\footnotetext{
${ }^{1}$ For the most recent period, life tables have been published each year by the Ukrainian Statistical Institute (see, for example, DKSU 2001, pp. 72-73), but they are biennial and not corrected for under-registration of infant deaths. Annual tables have been published by Anatoli Stephanoviskii (2001) for 1989-2006, but these too are not corrected for under-registration of deaths.
}

F. Meslé $(\varangle) \bullet J$. Vallin

Institut National d'Études Démographiques, Bd. Davout 133,

75980 Paris Cedex 20, France

e-mail: mesle@ined.fr; vallin@ined.fr

V. Shkolnikov

Max Planck Institute for Demographic Research, Konrad Zuse Strasse 1,

18057 Rostock, Germany

e-mail: shkolnikov@ demogr.mpg.de 


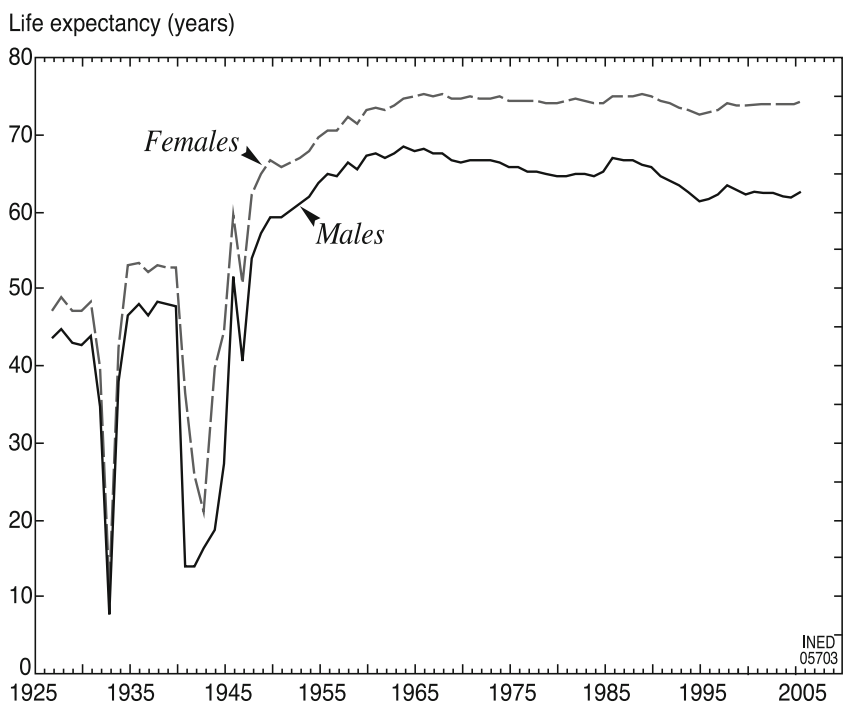

Fig. 5.1 Annual trends in life expectancy at birth, 1927-2006, by sex

\subsection{A Distinctive Trend in the Pattern of Age-Specific Mortality}

Figure 5.2 illustrates trends in the age-sex structure of mortality since the 1920 s. So that it will be easier to read, for earlier years it uses only the three biennial life tables calculated around the 1926, 1939 and 1959 censuses $^{2}$ (corrected for under-registration see Chaps. 2 and 4) and, for recent years, annual tables following one another at 10-year intervals - 1965, 1975, 1985 and 1995 (although the 2005 table has been replaced by the most recent one, calculated for 2006).

Despite the dramatic crises of the 1930s and 1940s, from 1926-1927 to 1958-1959, mortality declined in a very classic way in all age groups. In line with the conventional pattern, this reduction was especially strong among children and, in particular, adolescents (10-14 years, where the curve falls steeply to its lowest point), still significant for young adults and then limited in old age. No exception to this general downward trend can be found: all age groups benefited from it.

From the 1960s, the picture was entirely different. As early as the period 1958-1959 to 1965 , although the downward trend continued among the very young, no more headway was made at all beyond age 35 for men and age 45 for women: from these ages, the two mortality curves meet. This was the start of an increasingly unfavourable

\footnotetext{
${ }^{2}$ Since the 1926 census took place in December, the life table relates to the years 1926 and 1927. In contrast, the 1939 and 1959 censuses took place at the beginning of January, so the life tables relate to the years 1938-1939 and 1958-1959.
} 

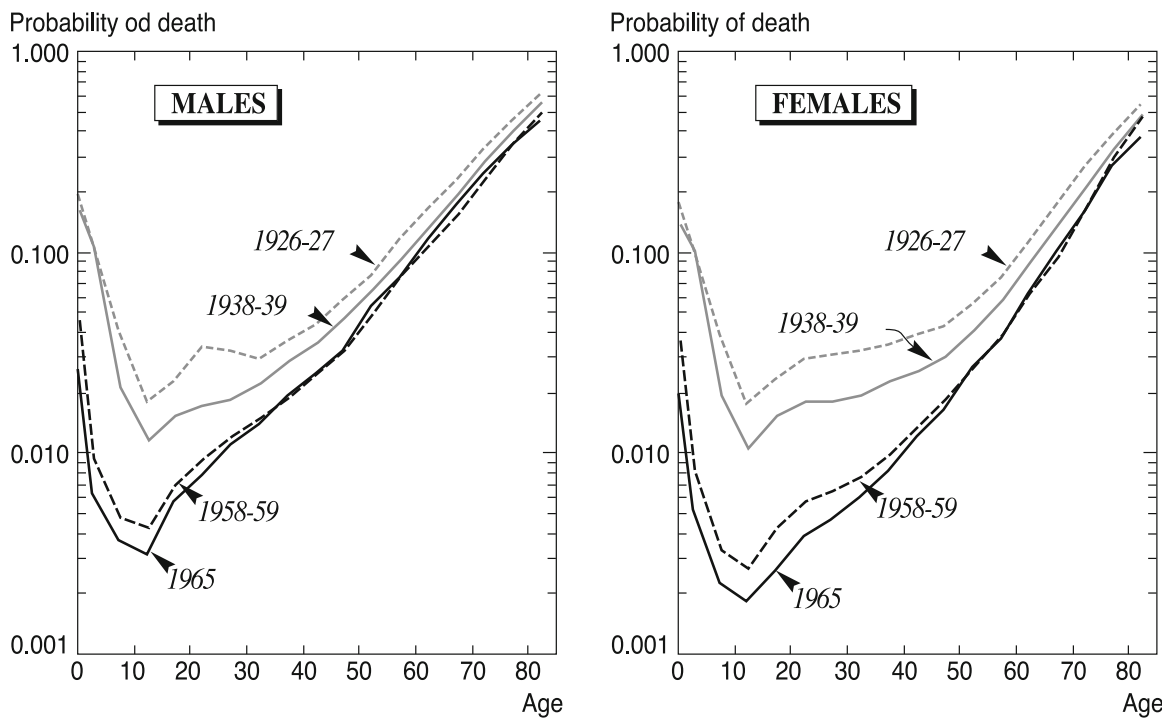

Probability of death

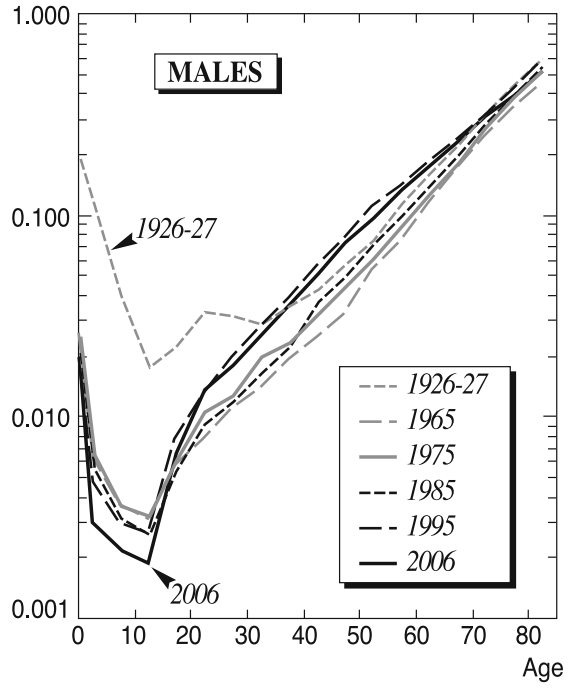

Probability of death

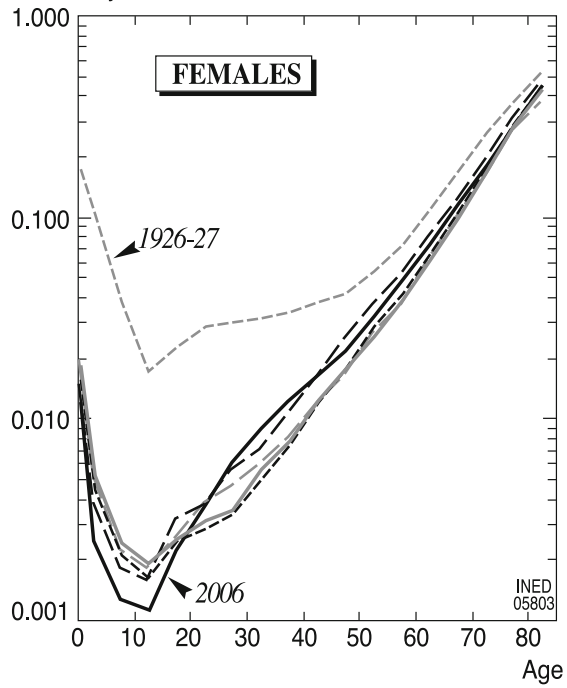

Fig. 5.2 Change in age-specific probabilities of dying, from 1926-1927 to 2006

trend, in which, firstly, improvements among the very young slowed down and, secondly and more especially, an upward mortality trend was established on a lasting basis among adult males. Among females, the rise in adult mortality has appeared only in the most recent period, but this follows 20 years of stagnation.

Among men, the outcome is striking: from the ages of 35 to 75 , probabilities of dying were higher in 1995 than they had been before the Second World War. 

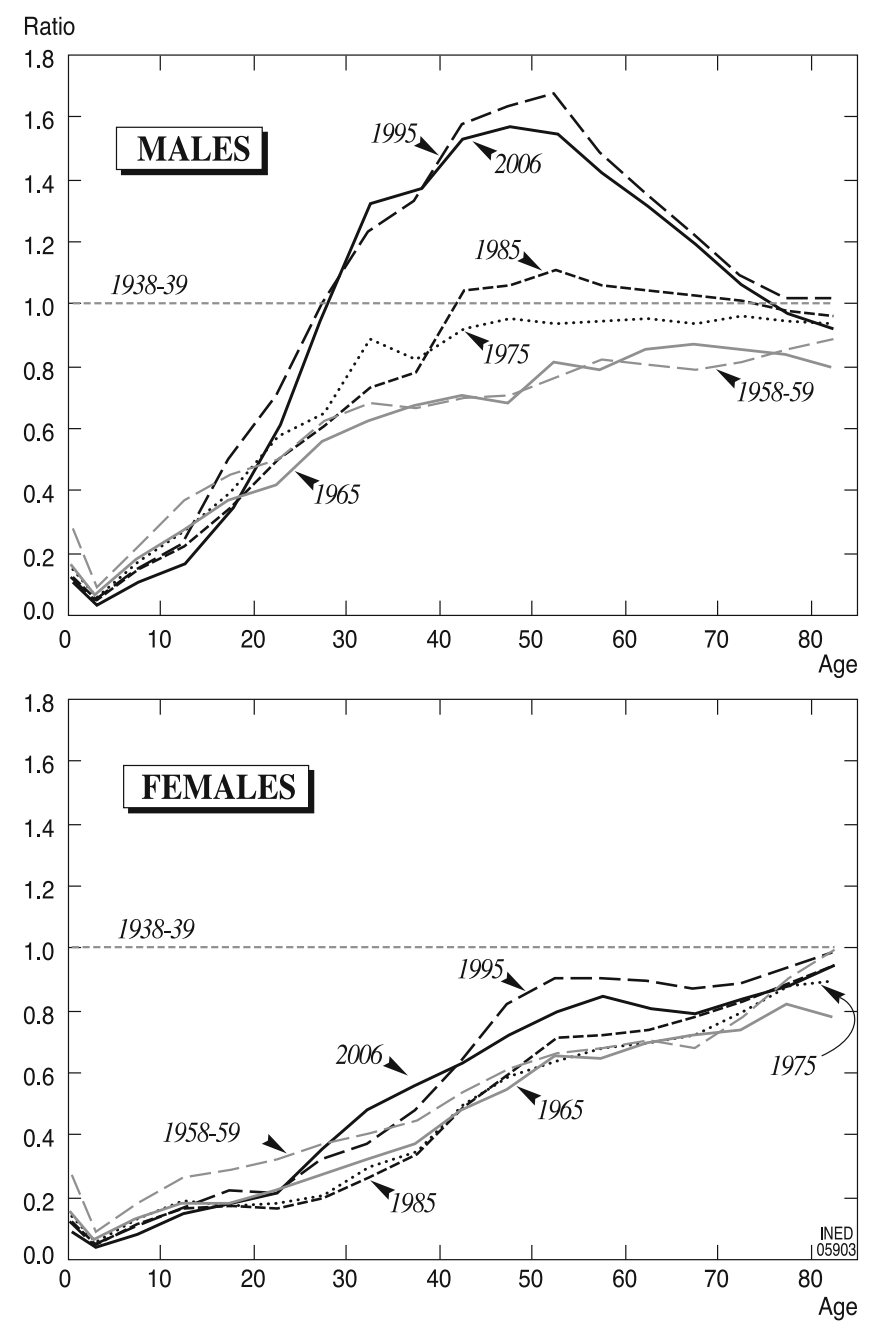

Fig. 5.3 Age-specific probabilities of dying from various life tables, compared to those from the 1938-1939 table

Between the ages of 40 and 55, they exceeded the 1938-1939 level by $60-70 \%$ and were even far above the 1926-1927 level.

In the last decade, deformation of the age structure of mortality has been further accentuated, with a rapid fall among the very young (aged between 1 and 15) contrasting with total stagnation in the adult age groups and even deterioration among women aged 25-40.

Figure 5.3 clarifies the extent of this phenomenon by comparing the observed age-specific probabilities of dying in these different periods with those from the 
1938-1939 table. Among males, it can be seen that the deterioration in adult survival that became more permanently established from 1965 onwards has worsened dramatically in recent years. In 1985, probabilities of dying beyond the age of 40 came into line with and even slightly overtook 1938-1939 levels, but from 1985 to 1995 they saw a sudden, unprecedented rise, bringing them to the percentages mentioned above. By 2006, the situation was hardly any better.

On the female side, this two-phase trend is encountered in another form; in this case, a long period of stagnation was followed by an abrupt deterioration between 1985 and 1995. The curve drawn for 2006 shows that there has been a much greater relative improvement than for males, with the current situation lying more or less halfway between the 1985 and 1995 curves.

The exceptional nature of this trend in mortality in Ukraine seems even clearer when we compare it to that of Western European countries. So, for males, Fig. 5.4a compares Ukrainian probabilities of dying in these different eras to French probabilities of dying calculated for the same dates.

In 1938-1939, the level of mortality among the very young in Ukraine was much higher than in France (twice as high under 1 year old, and a full 41/2 times higher at ages 1-43), but over the age of 20 it was consistently lower than in France. In 1995, on the other hand, while the difference in infant mortality between the two countries had hardly changed, the probabilities of dying were higher in Ukraine than in France for all age groups, and the gap between the two countries was particularly wide between the ages of 30 and 60 . Here too, it can be seen that this unfavourable trend in adult mortality in Ukraine gradually became established from 1965 onwards, but worsened dramatically after 1985 . This deterioration has continued in the last decade, though mainly to the detriment of men aged 25-45. At ages 30-35, excess mortality in Ukraine has increased more in the last 10 years than in the previous 40 years. But basically this deterioration is relative: the gap has widened much more because of improvements in France than because of negative trends in Ukraine.

Conversely, comparison with Russia shows clearly that the age structure of Ukrainian mortality has followed a trend very similar to and concomitant with that of Russian mortality (Fig. 5.4b). Certainly, the situation in Ukraine, which seemed terrible in the earlier comparison with France, here looks slightly more favourable, but that in no way prevents identical phenomena from coming into play, since whatever the period - the gap between Ukrainian and Russian risks remains more or less the same and hardly varies with age. The highly characteristic feature of deteriorating adult mortality, which we have already highlighted for Russia (Meslé et al. 1996, pp. 14-15), is reproduced line for line in Ukraine.

\footnotetext{
${ }^{3}$ In reality, perhaps this contrast between infant mortality and mortality at ages $1-4$ is exaggerated, since it may be that some infants who died towards the end of their first year of age were classified in the 1-4 age group instead of the group under 1 year old (see Chap. 4).
} 


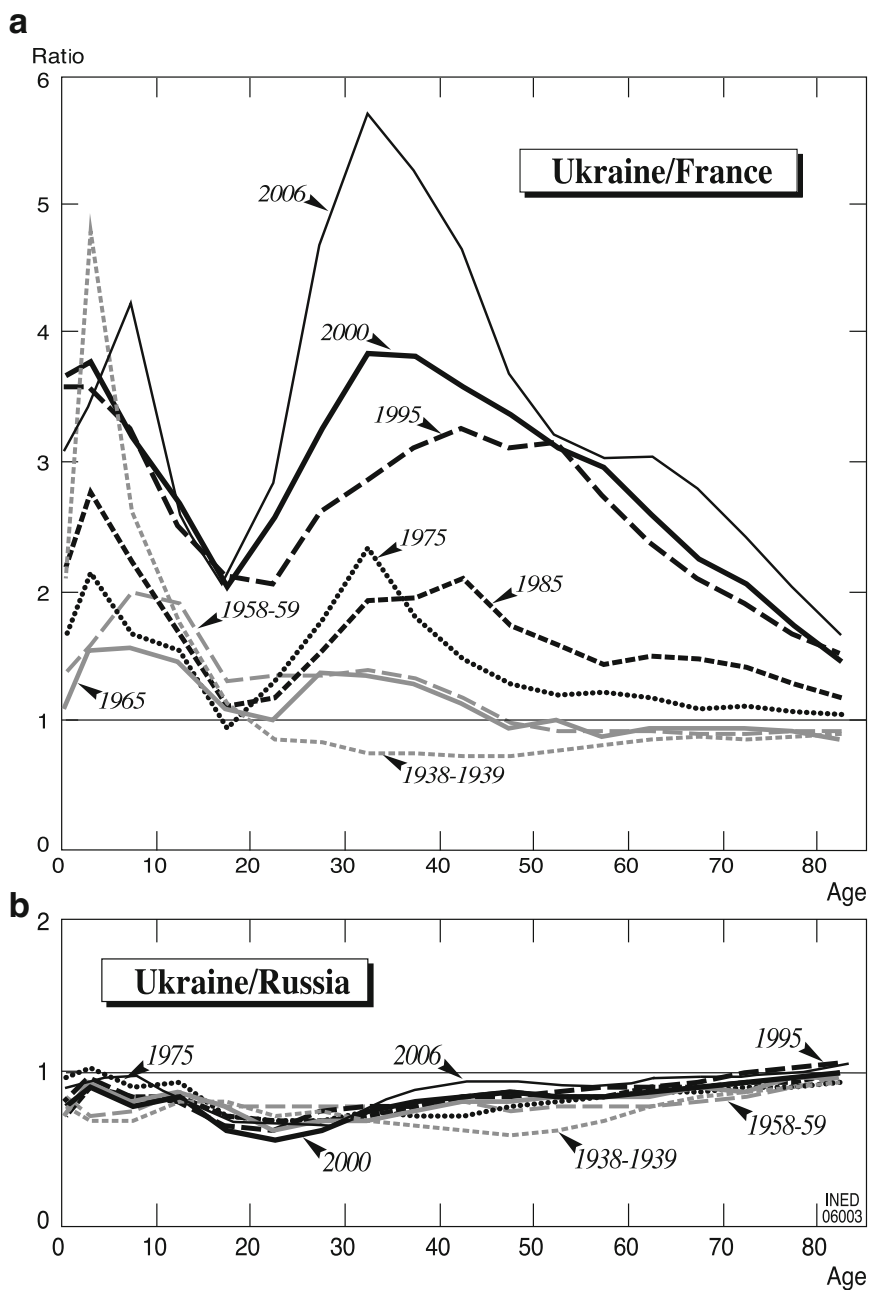

Fig. 5.4 Age-specific male probabilities of dying in Ukraine, from various life tables, compared to (a) French probabilities of dying and (b) Russian probabilities of dying observed in the same era

\subsection{The Influence of Various Age Groups on Changes in Life Expectancy}

Using, inter alia, the results of the estimates made in Chaps. 2 and 3, Figs. 5.5 and 5.6 trace annual trends in 5-year probabilities of dying from the mid-1920s. However, in order to make the figures more legible, the crisis years (1932-1934 and 1941-1947) are not shown here. This makes it much easier to judge the continuity of trends in the absence of crisis. These two figures highlight the striking contrast 

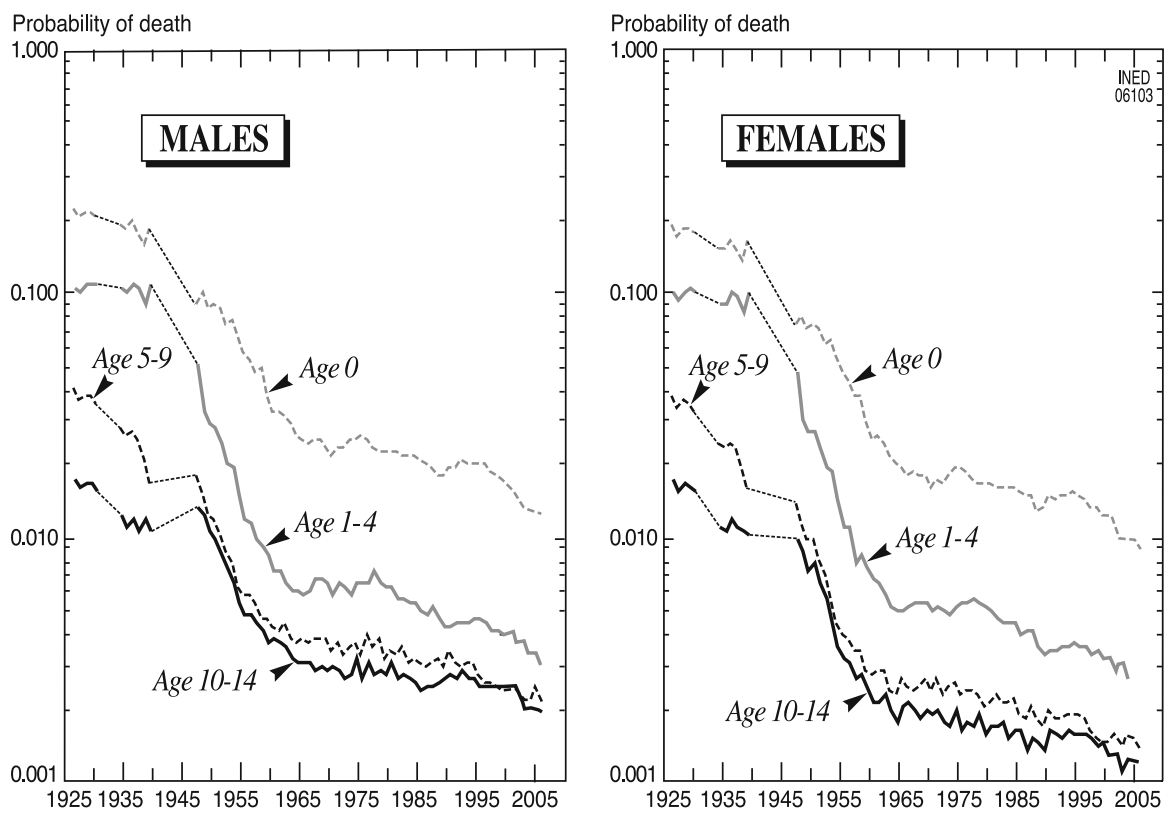

Fig. 5.5 1927-2006 trends in probabilities of dying for the first four age groups $(0,1-4,5-9$ and 10-14 years of age), from abbreviated life tables
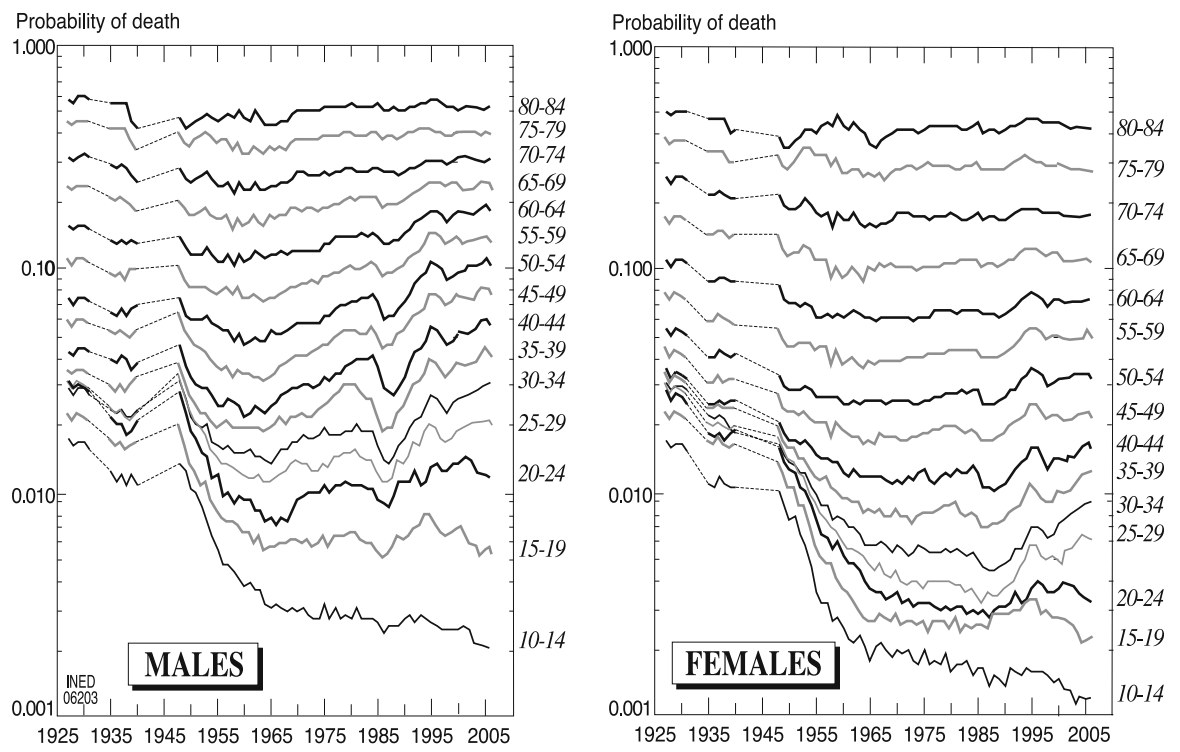

Fig. 5.6 1927-2006 sex-specific trends in 5-year probabilities of dying beyond age 10 
between the period running from the pre-War years to the mid-1960s, which - if we disregard the crisis years - shows a very rapid overall reduction in mortality, and the subsequent period, which, when mortality was not actually rising, was marked by stagnation.

The most recent period has been marked by stronger differences in trends between age groups: for children under 10 years of age, the downward trend in mortality has accelerated; the long period of stagnation for young people aged 10-25 has come to an end; however, mortality has increased in all the adult age groups.

In order to clarify the role played in life expectancy by these mortality trends at different ages, we created five large age groups, merging the 5-year groups whose trends, as shown in Figs. 5.5 and 5.6, were most alike. The first group brings together children from 0 to 14 years of age. This is because, at all these ages, the dominant factor was the rapid decline in mortality between 1938-1939 and 1965. Their subsequent course was fairly monotonous, and almost stagnant until it accelerated again recently (Fig. 5.5). The second group covers young people and adults from 15 to 34 years of age; they have also enjoyed a fairly large fall in mortality since the pre-War period, but in recent years have experienced somewhat marked fluctuations (Fig. 5.6). The third group is made up of adults aged 35-54: these are the people who bore the full brunt of the deterioration in the 1960s and 1970s, as well as of the major fluctuation in the 1980s. With the fourth group, aged 55-69, we are dealing with age bands that also experienced a strong post-1965 decline, but were less affected by the 1980s fluctuation. Finally, the fifth group, which brings together people over 70 years of age, is characterized by the most monotonous trends of the whole period.

Next we shall endeavour to measure the respective roles of these five large age groups $(0-14,15-34,35-54,55-69,70$ and over), firstly in the life expectancy gains of the anni mirabiles ${ }^{4}(1938 / 1939-1965)$ and losses of the anni horribiles (1965-2006), and secondly in the gender gap in life expectancy and its trends; we shall again make use of comparisons with France and Russia. ${ }^{5}$ The breakpoint in 1965 marks the change from a period of major improvements in health to a period of persistent crisis.

\footnotetext{
${ }^{4}$ However, these gains should obviously not lead us to forget the terrible crisis with which this period began, with the Second World War and the Stalinist repression (Chap. 3). The rise in life expectancy over the course of this period is nothing short of remarkable.

${ }^{5}$ The problems of under-registration of deaths that led us to correct Ukrainian infant mortality over the whole period and old-age mortality up to 1964 also arise in relation to Russia (Shkolnikov et al. 1995a, b). In our book on Russia (Meslé et al. 1996), we made several hypotheses about the extent of under-registration, but abandoned the idea of making any corrections, since these would have had hardly any influence on cause-specific mortality trends from 1965 to 1995. Having embarked on an exploration of the past in order to enhance our analysis for Ukraine, it was essential to correct the crude data; then, in order to ensure overall consistency, we extended our corrections to the whole period under study. In order to make these corrected Ukrainian data comparable to the Russian data, here we have applied the same corrections to Russia.
} 


\subsubsection{Life Expectancy Gains (1938/1939-1965) and Losses (1965-2006)}

Between 1938-1939 and 1965, life expectancy in Ukraine rose from 48.0 to 67.6 years for men and from 52.9 to 74.6 years for women. What role did mortality trends in the different age groups play in this gain of 19.6 years for men and 21.7 years for women? Several writers have proposed methods that allow a gap in life expectancy to be broken down according to age-specific mortality differences (Andreev 1982; Pollard 1982, 1990; Pressat 1985); all of them give extremely similar results. The results that follow were obtained by applying Andreev's method.

During this period, the very large gains in life expectancy obtained in Ukraine were entirely thanks to the fall in child mortality. The reduction in mortality at 0-14 years alone explains 15.4 years' improvement for males (Fig. 5.7a) and 14.9 years for females (Fig. 5.7c), representing $79 \%$ and $69 \%$ of the total gain for the respective sexes. Although the dominant role of the fall in mortality in these age groups was a little less pronounced among females, that is because in this period there was also a fairly significant reduction in female adult mortality, notably between the ages of 15 and 34, resulting from reduced fertility and improved childbirth conditions and delivery outcomes. This is also the factor that led to females enjoying greater longevity than males. But, overall, for both sexes, increased longevity was really due mainly to the fall in infant and child mortality.

What happened in Russia in the same period was entirely comparable (Fig. 5.7a, c). Of course, in starting from a slightly lower level of life expectancy, Russia made even more progress than Ukraine, with mean length of life rising from 39.6 years in 1938-1939 to 64.0 in 1965 for males and from 46.1 to 73.3 years for females - an increase of 24.4 and 27.2 years respectively (as against 19.6 and 21.7 in Ukraine). But the role of the fall in child mortality was just as dominant: $76 \%$ for males and $70 \%$ for females (so in Russia too, the place of other age groups was a little more significant for females than for males).

Things in this regard were completely different in France (Fig. 5.7a, c). Firstly, advances in life expectancy were much smaller. French males, who already had a life expectancy of 56.2 years in 1938-1939, saw an increase of only 11.6 years by 1965, as against 19.6 years for Ukrainian males; while females, starting from 62.3 years, gained only 12.8 years, as against 21.7 for Ukrainian females. This was the period when the countries of Eastern Europe, in particular Russia and Ukraine, made great strides in catching up on Western Europe. Secondly, French life expectancy gains were much less dominated by a fall in mortality at ages $0-14$. With gains of 5.0 years for males and 4.5 for females, the fall in mortality at these ages was responsible for only $43 \%$ and $35 \%$ of the respective total increases in life expectancy. For both males and females, the decline in mortality between the ages of 15 and 54 produced more additional years of life than the fall in child mortality. Moreover, for French females, the increasing role of the downward trend in mortality in older age groups is already apparent during this era: it was responsible for 1.8 years of additional life expectancy at ages 55-69 and for another 2 years at age 


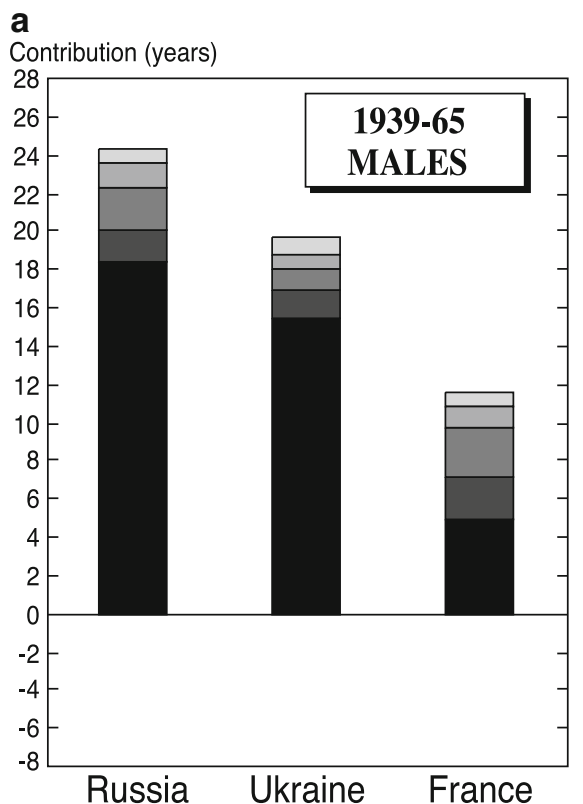

Contribution (years)

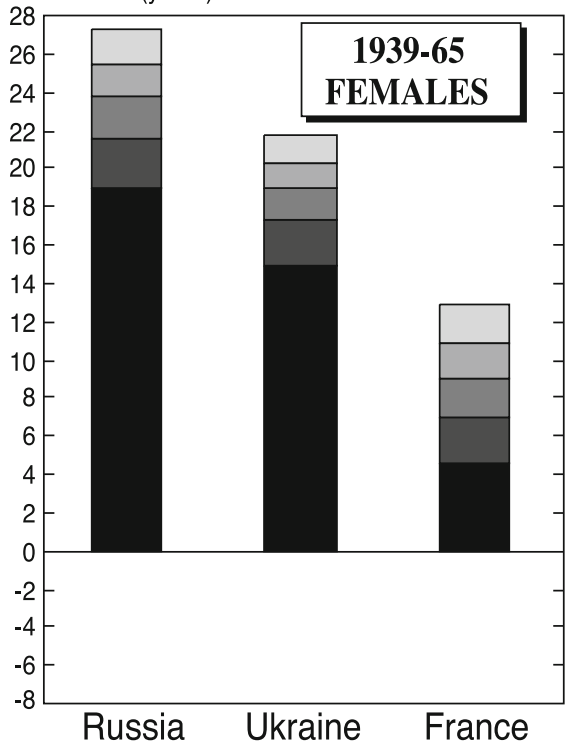

b

Contrbution (years)
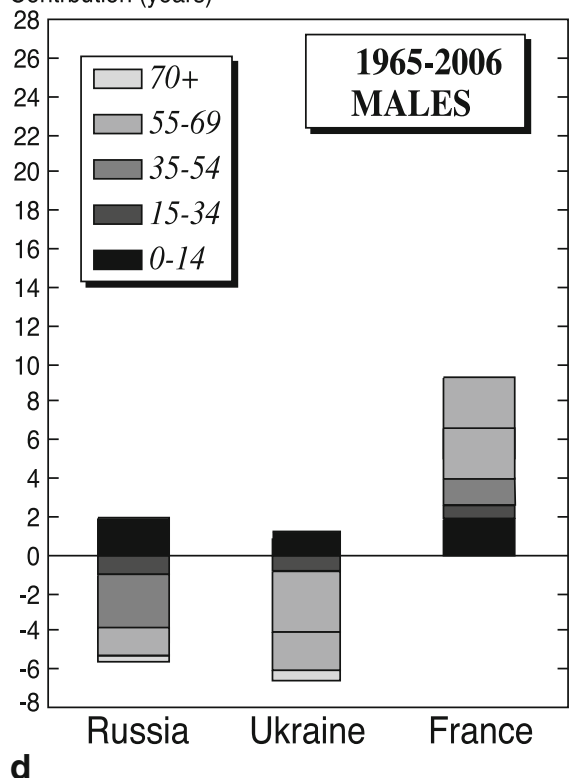

Contribution (years)

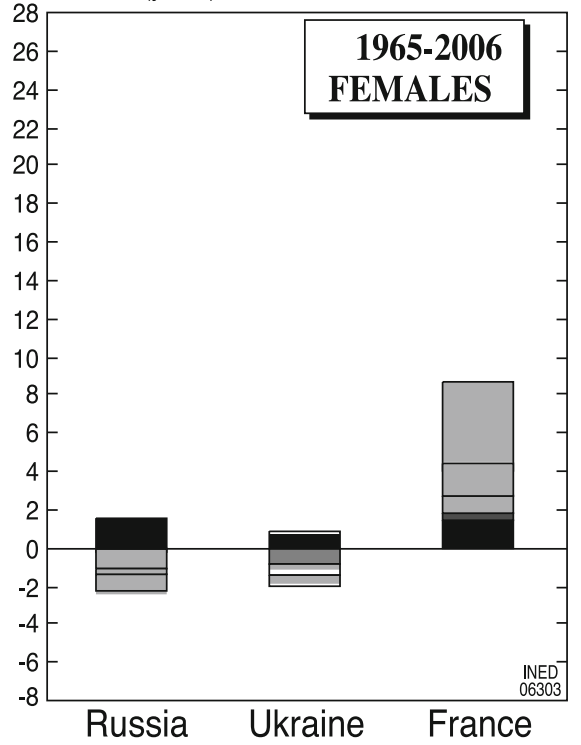

Fig. 5.7 Influence on life expectancy trends of variations in mortality between different age groups 
70 and over, representing a full $30 \%$ of overall gains (as against only 13\% among Ukrainian females).

The contrast between Ukraine and Russia, on the one hand, and France, on the other, is even more striking when we look at the second period, 1965-2006, which was characterized by a reduction in life expectancy in the first two countries at a time when advances were still being made in France (Fig. 5.7b and d). During this period, Ukrainian males lost 5.4 years and Ukrainian females, 0.9 years. The trend in mortality at ages under 15 was still the sole source of life expectancy gains, but was extremely limited: over a 40-year period, falls here produced gains of only 1.2 years for males and 1.0 years for females. In all the other age groups, increased mortality led to loss of years of life. The phenomenon was very marked among males, notably aged between 35 and 70 . This increase led to their losing 3.1 years of life expectancy at 35-54 years of age, and another 1.9 years at 55-69 years of age; these two age groups alone explained $92 \%$ of the total reduction in male life expectancy. Among females, the losses, which were smaller, were divided between mature adults and the old. During this period, trends observed in Ukraine were more unfavourable than those in Russia, where gains from the downward trend in mortality at ages under 15 were higher and losses due to the increase in adult mortality, slightly lower. On the other hand, both countries stand in stark contrast to France, where not only did life expectancy continue to grow, but the fall in adult mortality, and above all in mortality at ages over 70, played an increasingly overwhelming part ( $47 \%$ of the 8.9 years gained by females).

\subsubsection{Age Groups and the Gender Gap in Life Expectancy}

On the eve of the Second World War, the gender gap in life expectancy was significantly narrower in Ukraine (4.9 years) than the observed difference in France (6.2) and in Russia (6.5). After that, this gap widened in all three countries, but more rapidly in Ukraine and more rapidly still in Russia (Fig. 5.8). In 1965, with a gap of 7.0 years, Ukraine was at more or less the same level as France (7.3), while Russia had already reached 9.3 years. This trend subsequently became even more pronounced: in 2006, there was a gap of 6.9 years in France, compared to 11.5 years in Ukraine and 12.9 in Russia.

In order to assess the roles of the different age groups in these gender gaps in life expectancy, we again used Evgenii Andreev's method of breaking them down (Fig. 5.8).

Infant and child mortality, which had played a major role before the Second World War - especially in Russia and Ukraine, but to a lesser extent also in France was already playing only a marginal one by 1965 , and had almost negligible influence by 2006. The way in which the influence of child mortality on the gender gap was eclipsed was almost identical in all three countries; the only difference was in the time-lag relating to the tempo of the reduction in infant mortality in each case. 


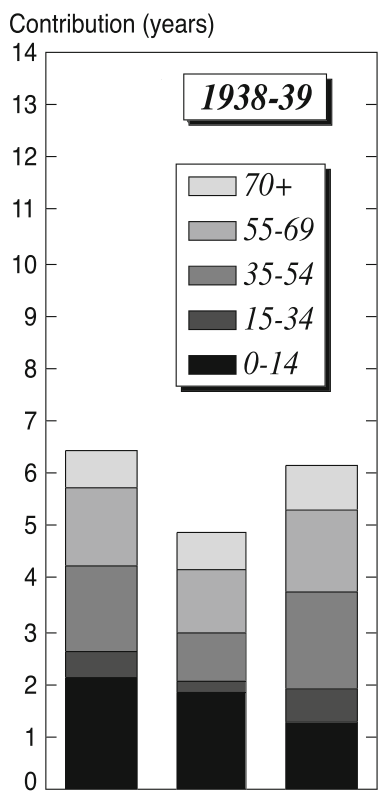

Russia Ukraine France
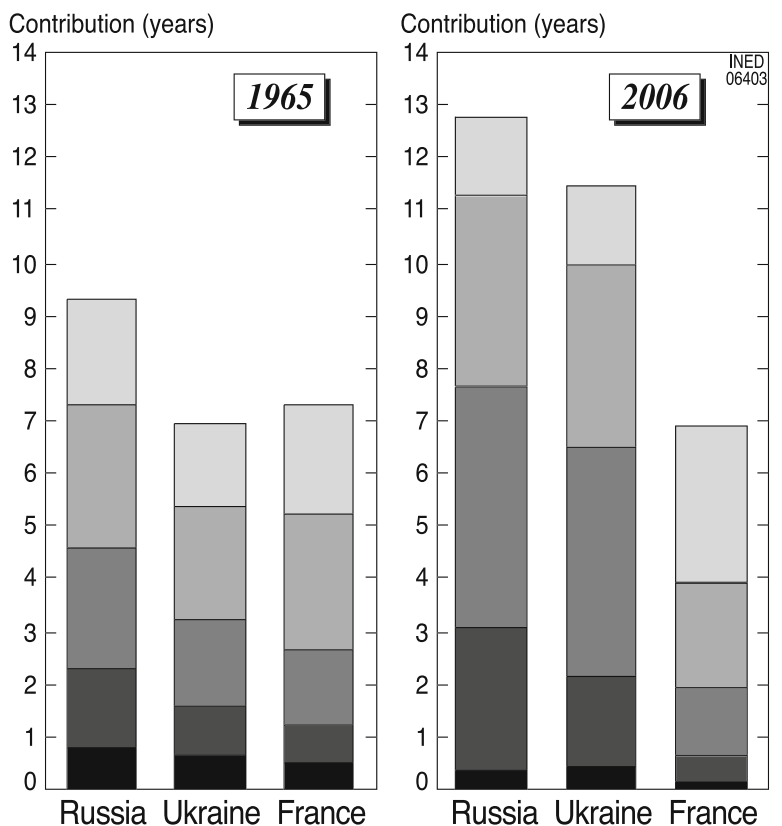

Fig. 5.8 Influence on the gender gap in life expectancy of differences between sex-specific mortality in various age groups

Up to 1965, in all three countries, it was more or less the same age groups that eclipsed infant mortality in this way; they even made the gender gap worse, with the 55-69 age group in particular playing a major role. This was because, during this period, female mortality in this age group declined much more quickly than male mortality.

On the other hand, after 1965, the gender gap developed in different ways and depended on very different factors (Fig. 5.8). In Ukraine, as in Russia, ${ }^{6}$ the gap widened dramatically under the impact of the increase in mortality in adult age groups, which was much greater for men than for women. So, in 2006, 4.4 years of the gender gap of 11.5 years in Ukraine were due to the difference in mortality at $35-54$ years of age, and 3.5 years to the difference in mortality at 55-69. These two age groups alone explain $68 \%$ of the total gap, while in 1965 they explained only $54 \%$ (3.8 years out of 7.0). In 2006, the same two age groups explained $64 \%$ of the gender gap in Russia (8.3 years, out of 12.9), while in 1965 they explained only $54 \%$ (5 years out of 9.3). In France, in contrast, the gender gap in life expectancy stopped increasing in the 1980 s and started to decline significantly from the $1990 \mathrm{~s}$ (Meslé 2004). In 2006, it was only 6.9 years - slightly less than in 1965 (7.3).

\footnotetext{
${ }^{6}$ For Russia, this point is developed more fully in Meslé and Vallin (1998).
} 
However, the age groups that contribute the most to this have changed: in 1965, it was people aged 55-69 who created most of the gap (2.6 years out of 7.3), while in 2006 it was those aged over 70 (3.0 years out of 6.9).

\section{References}

Andreev, E. (1982). Метод компонент в анализе продолжительности жизни [Analysis of life expectancy using component methods]. Вестник статистики [Bulletin of Statistics], 3 (March), 42-47.

Dksu (Derzhavnyi Komitet Statystyky Ukraïny) (2001). Населення Украіни 2000. Демографічний щорічник [The population of Ukraine 2000. Demographic Yearbook] (515 pp.). Kiev: State Statistics Committee of Ukraine.

Meslé, F. (2004). Écart d'espérance de vie entre les sexes: les causes du recul de l'avantage féminin. Revue d'épidémiologie et de santé publique, 52(4), 333-352.

Meslé, F., \& Vallin, J. (1998). Évolution et variations géographiques de la surmortalité masculine: du paradoxe français à la logique russe. Population, 53(4-5), 1079-1102.

Meslé, F., Shkolnikov, V. M., Hertrich, V., \& Vallin, J. (1996). Tendances récentes de la mortalité par cause en Russie 1965-1994. Paris: INED and CDEH (Bilingual French and Russian publication. Données statistiques, No. 2, 140 p. +2 diskettes).

Pollard, J. H. (1982). The expectation of life and its relationship to mortality. Journal of the Institute of Actuaries, 109(442), 225-240. Part 2.

Pollard J. H. (1990). Cause of death and expectation of life: some international comparisons. In J. Vallin et al. (Eds.), Measurement and analyses of mortality: new approaches (pp. 269-292, 416 p.). Oxford, Clarendon Press.

Pressat, R. (1985). Contribution des écarts de mortalité par âge à la différence des vies moyennes. Population, 40(4-5), 766-770.

Shkolnikov, V., Meslé, F., \& Vallin, J. (1995a). La crise sanitaire en Russie. I. Tendances récentes de l'espérance de vie et des causes de décès en Russie de 1970 à 1993. Population, 50(4-5), 907-943 (Subsequently published in English as: Shkolnikov, V., Meslé, F., \& Vallin, J. (1996). Health crisis in Russia I. Recent trends in life expectancy and causes of death from 1970 to 1993. Population: An English Selection, 8, 123-154).

Shkolnikov, V., Meslé, F., \& Vallin, J. (1995b). La crise sanitaire en Russie. II. Évolution des causes de décès: comparaison avec la France et l'Angleterre (1970-1993). Population, 50(4-5), 945-982 (Subsequently published in English as: Shkolnikov, V., Meslé, F., \& Vallin, J. (1996). Health crisis in Russia II. Changes in causes of death: A comparison with France and England and Wales (1970 to 1993). Population: An English Selection, 8, 155-189).

Stephanoviskii, A. (2001). Компонентний аналіз середньоі тривалості життя населення [Analyse des composantes de l'espérance de vie de la population] (128 p.). Kiev: Iнституm Економіки НАН Украіни [Institut d'économie de l'Académie nationale des sciences d'Ukraine]. 